\title{
¿Hay diferencias en la manera en que observan hombres y mujeres a los adultos mayores, ancianas y ancianos? ${ }^{1}$
}

\author{
Mag. Anahí Urquiza Gómez \\ Antropóloga Social - Universidad de Chile. Magíster en Antropología y Desarrollo - \\ Universidad de Chile \\ Programa Pulso, Facultad de Ciencias Sociales - Universidad de Chile \\ aurquiza@uchile.cl

\section{Dr. Marcelo Arnold-Cathalifaud} \\ Antropólogo Social - Universidad de Chile. Doctor en Ciencias Sociales - Universidad \\ de Bielefeld. Alemania \\ Observatorio Social de la Vejez y Envejecimiento en Chile, Facultad de Ciencias \\ Sociales - Universidad de Chile \\ marnold@uchile.cl
}

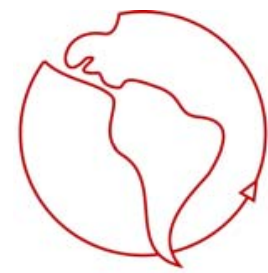

\section{Mg. Daniela Thumala Dockendorff}

Psicóloga - Universidad de Chile. Magíster en Antropología y Desarrollo - Universidad de Chile

Directora Ejecutiva. Fundación Soles

dthumala@soles.cl

\section{Mg. Alejandra Ojeda Mayorga}

Socióloga - Universidad de Chile. Magíster en Antropología y Desarrollo - Universidad de Chile

Directora de Estudios. Collect

aojeda@collect.cl

Resumen

El presente artículo trata sobre las diferencias y similitudes de percepción que hombres y mujeres jóvenes, tienen sobre la vejez y el envejecimiento, partiendo de la evaluación de los conceptos: adulto mayor, anciana y anciano. El análisis se apoya en corrientes del pensamiento gerontológico, destacando que muchas de las minusvalías de las personas mayores provienen de su exclusión social y de un contexto cultural desfavorable, más que del estado de sus organismos o condición mental. Cómo el género podría tener relación con la configuración de estas exclusiones, es el objeto de la investigación realizada entre jóvenes chilenos a partir de la aplicación de una prueba de diferencial semántico a 682 estudiantes universitarios de ambos sexos. Los resultados dan cuenta de una generalizada y consistente imagen negativa proyectada, por hombres y mujeres, sobre los tres conceptos. Si bien se aprecian algunas diferencias de género en las percepciones sobre la vejez éstas, no alcanzan a ser significativas, por lo que se concluye que las imágenes sociales sobre el envejecimiento trascienden las diferencias de género, dando cuenta de la fuerza y peso que tienen en la construcción de imágenes que pudieran estar afectando las expectativas de las actuales y futuras personas mayores.

\section{Abstract}

This article is about the differences and similarities in the perception that young people make about older ones, this from 3 basic concepts: older people, older 
woman and older men. The analysis stands over the gerontology field, which highlights that lot of the handicaps of the older people comes from their social exclusion and from an unfavourable cultural context, rather than from the state of their organisms or metal condition. How gender might be involved in the configuration of these exclusions is the object of this research, which one was made with 682 young, female and male, college students, who answered a differential semantic test. The results show a generalized and consistent negative image about older people, in both sexes over the three concepts. Even there are some differences between sexes in the perception of growing old, these are not significant, so, the conclusion is that the social images about growing old, transcend gender differences, showing the strength that they have in the construction of images that may be affecting the expectations of the older people, in the present and or in the future.

Palabras Clave: Chile, jóvenes, género, imágenes sociales, gerontofobia

Keywords: Chile, youngs, gender, social images, gerontophobia

\section{Introducción}

Son varios los países se hoy en día enfrentan a un acelerado envejecimiento de la población, Chile es uno de estos países. Con una población de 16.3 millones de habitantes, se encuentra en un importante proceso de cambio demográfico. La fecundidad ha disminuido y está llegando a un nivel por debajo del de reemplazo (Bravo, J. \& Bertranou, F. 2006), se observan menores tasas de mortalidad y la esperanza de vida, de acuerdo con el Instituto Nacional de Estadísticas, alcanza hoy día alrededor de los 78 años, lo que representa un incremento de más de 20 años en los últimos 50 años. En el año 2005 las personas mayores de 65 años constituían el 7,93\% de la población y en el 2050 llegarán al 21,59\% (Aguilera, 2005), lo cual explica el abrupto cambio en nuestro perfil demográfico, como se aprecia en el siguiente gráfico:

Gráfico 1: Chile: Distribución porcentual de la población por sexo, según grupos quinquenales de edad. Censo 2002 y estimada al 2050.
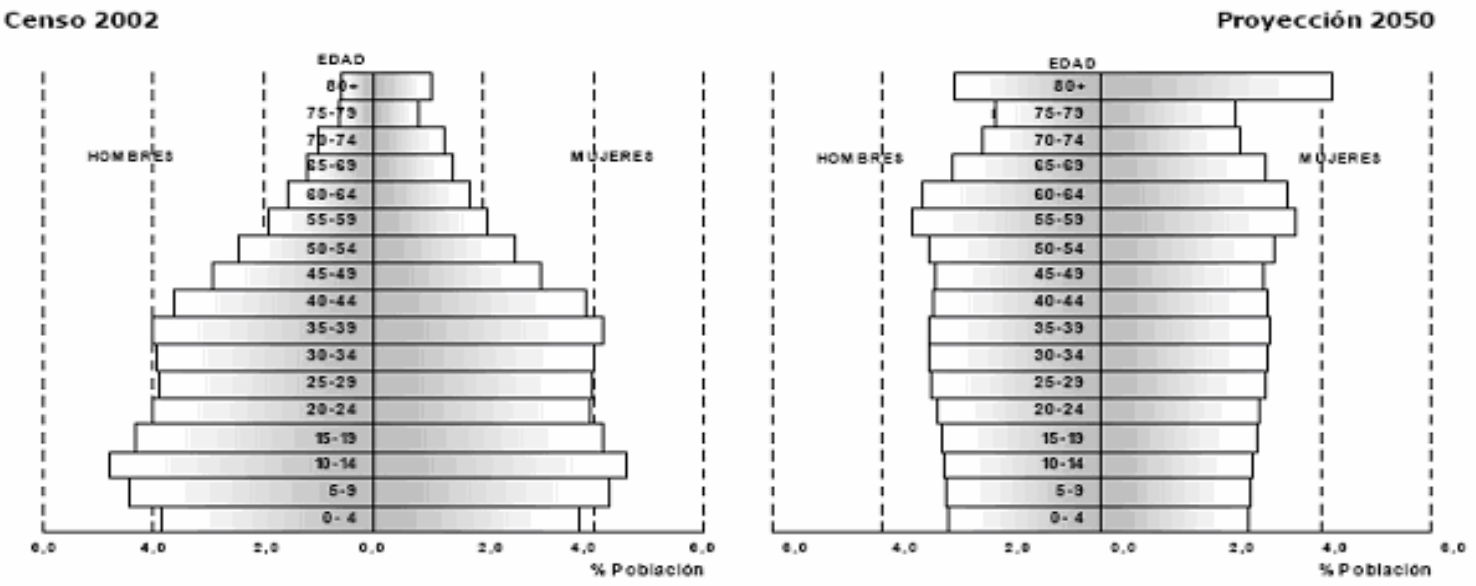

Fuente: INE (2004). Estimaciones y proyecciones de población por sexo y edad. Instituto Nacional de Estadística 
Como claramente se observa, las mujeres tienden a vivir más que los hombres. Este sólo dato puede ser un indicio de las diferencias que se podrían encontrar entre el envejecimiento masculino y femenino. En este sentido, Pinquart \& Sorensen (2001, en George, 2006) realizaron una investigación que consistió en un meta - análisis de 300 estudios sobre bienestar subjetivo: encontraron que las mujeres mayores reportaron un nivel significativamente menor de bienestar que los hombres mayores, lo cual podría tener relación con sus posibilidades de experimentar por más tiempo las condiciones de soledad, dependencia y exclusión social. Por su parte, Inglehart (2002, en George, 2006) realizó un estudio a 146.000 adultos en 65 diferentes países y encontró que las mujeres menores de 45 años dieron cuenta de mayores niveles de bienestar subjetivo que sus pares hombres, pero niveles inferiores de bienestar a partir de los 45 o más años.

Como sería esperable, si la variable género afecta el curso de la vida, claramente ello debería observarse la vejez. Tal y como señalan Moen y Spencer (2006), la forma en que se organiza la vida no sólo se relaciona con categorías de edad, en el sentido de lo que se entiende y se espera para cada etapa, sino también con las categorías de género, a partir de las cuales se aprecian diferencias en los cursos de vida de hombres y mujeres. Ahora bien, para estos mismos autores, la consideración sin mayor conciencia de estas categorías de edad y género determinan efectivamente las opciones de vida de las personas mayores, aún cuando se trate de categorías pasadas de moda, dados los cambios demográficos, laborales y tecnológicos. Ahora bien, sería esperable que estos cambios no sólo generaran ambigüedades en los propios involucrados, sino también en las imágenes que actualmente hombres y mujeres jóvenes tienen sobre la vejez y el envejecimiento y sus consecuencias, es decir con la manera en que este grupo etario es socialmente integrado y valorado. Esta situación estaría generando cierta incertidumbre y ambivalencia sobre la forma que debería tomar la vida en la vejez, promoviendo un proceso reflexivo en las personas mayores para enfrentar esta etapa.

Si bien las imágenes sociales sobre la vejez no revisten un carácter universal, estudios internacionales coinciden en señalar que contienen estereotipos con fuertes cargas negativas, alejándose así de lo que los adultos mayores pudieran efectivamente esperar ante los avances de la modernidad que han dado lugar a sus actuales expectativas de vida.

En una investigación realizada en España entre los años 2002 y 2003 (Adelantado et al., 2004) se observó que las imágenes generalizadas en torno a la vejez están lejos de representar lo que los mismos ancianos piensan y sienten respecto de ésta y de la forma en como ellos mismos se representan el transitar por dicha etapa. Ello estaría dando cuenta de una importante distancia entre las expectativas sobre la edad que son socialmente construidas con las vivencias personales de los viejos. Otros ejemplos, señalados por Tan et al (2004), muestran cómo en Estados Unidos, en el Sudeste de Asia y en el Caribe la vejez es asociada con rasgos negativos, tales como "triste", "inflexible", "no atractiva", por mencionar algunos.

En Chile, el Comité Nacional para el Adulto Mayor realizó, durante el año 2002, una encuesta orientada a conocer la percepción de los jóvenes sobre los adultos mayores. La muestra fue de 164 estudiantes de tercero medio de cinco colegios mixtos de la Región Metropolitana, cuyas edades fluctuaron entre los 15 y 18 años. Si bien se observaron algunas indicaciones positivas a la hora de evaluar a los adultos mayores, 
la presencia de estereotipos negativos fue evidente. Por esta razón, el Comité concluyó que era urgente, en el marco de políticas públicas, revertir las imágenes y actitudes negativas hacia el adulto mayor (Informe del Comité Nacional para el Adulto Mayor, 2002).

La mayoría de los estudios revisados muestran que las imágenes que construyen los jóvenes sobre la vejez, en general, se asocian a una valoración negativa de esta etapa de la vida. Sin embargo, a partir de éstos, no es posible conocer si el género, como variable que tradicionalmente se asocia a la forma en que se configuran las distintas etapas de la vida, afecta las expectativas sociales sobre la vejez. En parte, estas imágenes se reproducen profusamente en los medios de comunicación masivos, como ha sido destacado en una reciente investigación (Torrejón, 2007).

\section{Problema De Investigación: Aspectos Teóricos}

El estudio que presentamos a continuación, tuvo por objetivo conocer las similitudes y diferencias de percepción que los jóvenes chilenos universitarios, hombres y mujeres, tienen de la vejez a partir de tres conceptos: adulto mayor, anciana y anciano. A partir de sus resultados, invita a reflexionar sobre cuál podría ser el peso que la variable género tiene en la construcción de estas imágenes sociales. Específicamente, nos preguntamos si hay diferencias en la manera en que observan hombres y mujeres a los adultos mayores, ancianas y ancianos.

Nuestro punto de partida fue indagar las formas de distinción que los jóvenes, hombres y mujeres, aplican a la condición de vejez. Para ello nos basamos en una propuesta teórica vinculada estrechamente con los planteamientos sistémicos y constructivistas que sostienen que todo lo que se produce y reproduce como conocimiento, incluyendo imágenes, estereotipos o expectativas, remite a operaciones de observación determinadas por las posibilidades y condiciones presentes en la sociedad (Luhmann, 1998). Desde esta perspectiva, denominada sociopoiética (Arnold, 2003) se pueden describir las diferentes racionalidades constituyentes de la realidad social y reconocer la aguda diferenciación de la sociedad, lo cual estimula el entendimiento de fenómenos que carecen de referencias unívocas.

El programa sociopoiético es apropiado para observar la vejez, en tanto las atribuciones con que se designan los contenidos vivenciales y experienciales de cada etapa de la vida, se producen desde los esquemas de distinción a partir de los cuáles se forman las expectativas sociales que aumentan las probabilidades de que las comunicaciones y acciones sigan ciertas direcciones y no otras. En este sentido resulta interesante observar en las comunicaciones de nuestra sociedad, cómo se observa la vejez, en tanto se empalman con expectativas tipificadas de comportamientos.

\section{Aspectos metodológicos, muestra y procedimientos}

Para registrar las distinciones que se aplican a la vejez se aplicó una prueba del tipo diferencial semántico (Osgood et al, 1957) que resulta particularmente útil para estudios que se basan en construcciones de imágenes evaluativas respecto de objetos sociales. El instrumento estuvo compuesto por un conjunto de pares de adjetivos, seleccionados a partir de la literatura especializada, que permiten discriminar atribuciones sobre la vejez. Para seleccionar los adjetivos que finalmente conformaron el instrumento, la prueba fue testeada mediante su aplicación y análisis piloto a una muestra de 60 estudiantes universitarios y sometida a la evaluación de expertos en la 
materia. A partir de este proceso se seleccionaron los siguientes pares de adjetivos: independiente/dependiente; productivo/improductivo; eficiente/ineficiente; hábil/torpe; saludable/enfermizo; sexualmente activo/sexualmente no activo; frágil/resistente; sociable/retraído; tolerante/intolerante; confiado/desconfiado; progresista/conservador; no conflictivo/conflictivo; ciudadano activo/ciudadano pasivo; protegido/desamparado; integrado/marginado y valorado/desvalorado. Estos adjetivos se proyectaron como escalas bipolares frente a los estatuses de Adulto Mayor, Anciano y Anciana, los que para efecto de este tipo de prueba cumplen la función de reactivos. Luego, tanto los pares de adjetivos como la ubicación en que los aspectos "positivos" y "negativos" de cada par fueron presentados de forma aleatoria. Finalmente, se fijó una distancia de 7 puntos entre sus versiones extremas, de modo de que los encuestados pudieran marcar a qué distancia de cada extremo ubicaban a cada uno de los reactivos para cada uno de los 16 pares de adjetivos presentados. La estrategia de recolección de datos consistió en la aplicación de un cuestionario autoadministrado con instrucciones a seguir, como se muestra en el siguiente Cuadro:

Tabla № 1: Formato de la prueba diferencial semántico

\begin{tabular}{|ccc} 
& REACTIVO & \\
& (Adulto Mayor, Anciana, Anciano) \\
Independiente & D \\
\hline Productivo & $\square \square \square \square \square \square \square$ & Dependiente \\
\hline Saludable & $\square \square \square \square \square \square \square$ & Improductivo \\
\hline Intolerante & $\square \square \square \square \square \square \square$ & Enfermizo \\
\hline Eficiente & $\square \square \square \square \square \square \square$ & Tolerante \\
\hline Frágil & $\square \square \square \square \square \square \square$ & Ineficiente \\
\hline Progresista & $\square \square \square \square \square \square \square$ & Resistente \\
\hline Ciudadano pasivo & $\square \square \square \square \square \square \square$ & Conservador \\
\hline Desamparado & $\square \square \square \square \square \square \square$ & Ciudadano activo \\
\hline Sexualmente activo & $\square \square \square \square \square \square \square$ & Sexualmente no-activo \\
\hline Hábil & $\square \square \square \square \square \square \square$ & Torpe \\
\hline Integrado & $\square \square \square \square \square \square \square$ & Marginado \\
\hline Confiado & $\square \square \square \square \square \square \square$ & Desconfiado \\
\hline Conflictivo & $\square \square \square \square \square \square \square$ & No conflictivo \\
\hline Sociable & $\square \square \square \square \square \square \square$ & Retraido \\
\hline Valorado & $\square \square \square \square \square \square \square$ & Desvalorado \\
\hline
\end{tabular}

Para realizar el análisis se recodificaron los valores de los peldaños entre pares de adjetivos, de manera que siempre el valor más alto se asociara al adjetivo de connotación positiva y el valor más bajo al adjetivo de connotación negativa. Con el fin de observar las tendencias de los estudiantes para evaluar los tres reactivos, se determinó que los puntajes 5, 6 y 7 marcarían la tendencia hacia al extremo "positivo" del par adjetivo, el valor 4 representaría una posición neutral y los puntajes 1,2 y 3 señalarían la tendencia hacia el extremo "negativo" del par adjetivo. Por ejemplo, frente al par "independiente - dependiente", las puntuaciones 5, 6 y 7 indicarían una tendencia hacia el extremo "independiente", el puntaje 4 una posición neutral y los valores 1, 2 y 3 una tendencia hacia el extremo "dependiente". Finalmente, se calcularon frecuencias de respuesta, porcentajes de las mismas, medidas de tendencia central y comparaciones entre porcentajes y promedios de submuestras con pruebas de diferencias significativas ( alfa $=0.05$ ). 
El diseño fue de naturaleza no probabilística, basándose específicamente en el modelo de muestreo por conveniencia que opera desde la selección no aleatoria de unidades bajo criterios de contactación en grupos que forman parte del universo definido como objetivo y cuya disponibilidad es la más conveniente (Zikmund, 1998). El universo teórico del estudio correspondió a los estudiantes de educación superior universitaria de pre-grado de instituciones con sede en la Región Metropolitana pertenecientes al Consejo de Rectores de las Universidades Chilenas. Sin embargo, al utilizarse una muestra cautiva de alumnos de los Cursos de Formación General que se imparten en la Universidad de Chile, el universo real se delimitó a este grupo. Considerando que el total de la matricula de alumnos del universo teórico es 87.923, la Universidad de Chile alcanza al $24 \%$ del total (24.502 alumnos de pre-grado). Si bien se trata de una muestra generada en base a un diseño no probabilístico, la simulación del cálculo de error indica que de tratarse de una muestra aleatoria su margen de error hubiese sido $+-3,7 \%$ bajo supuesto de máxima varianza.

El tamaño de la muestra alcanzó a 682 alumnos de diversas carreras y estuvo compuesta por un $50,3 \%$ de hombres y un $49,7 \%$ de mujeres, proporción similar al parámetro nacional y a la matrícula de alumnos de pre-grado de la educación superior universitaria del país. La edad promedio de los encuestados fue de 20,16 años quedando el $76,4 \%$ de la muestra concentrada en el tramo de 18 a 21 años.

\section{I. Resultados}

Los resultados que presentamos se organizan en dos partes: la primera se refiere a la comparación de respuestas ante los pares de adjetivos por género y reactivo, la segunda parte hace referencia a la consistencia de las respuestas según género.

\section{Comparación de pares de adjetivos por género y reactivo}

A pesar de que en términos generales, no se observaron diferencias significativas entre las percepciones de hombres y mujeres, el análisis de cada uno de los pares de adjetivos permitió identificar algunas diferencias de género relevantes en la evaluación de adulto mayor, anciana y anciano, como se observará en la siguiente presentación de resultados.

Respecto de la "dependencia" o "independencia" que se le atribuye a la etapa de la vejez, aparece una clara tendencia a evaluar a las personas mayores como "dependientes". Ahora bien, la comparación de las tendencias observadas entre adulto mayor, anciana y anciano, para el caso de mujeres y hombres, nos muestran algunas diferencias interesantes. Las mujeres mostraron diferencias significativas al evaluar a ancianos y ancianas, donde más mujeres evalúan como dependientes a los ancianos (71\%) que a las ancianas (63\%). En el caso de la evaluación realizada por los hombres, las diferencias las encontramos entre adulto mayor $(61 \%)$ y anciana (71\%), y entre ésta y anciano $(60 \%)$, en ambos casos las ancianas aparecen como significativamente más dependientes que ancianos y adultos mayores. 
Gráfico № 2: Tendencias obtenidas por hombres y mujeres en el par "Dependiente / Independiente", expresadas en porcentajes.

\section{Dependiente / Independiente}

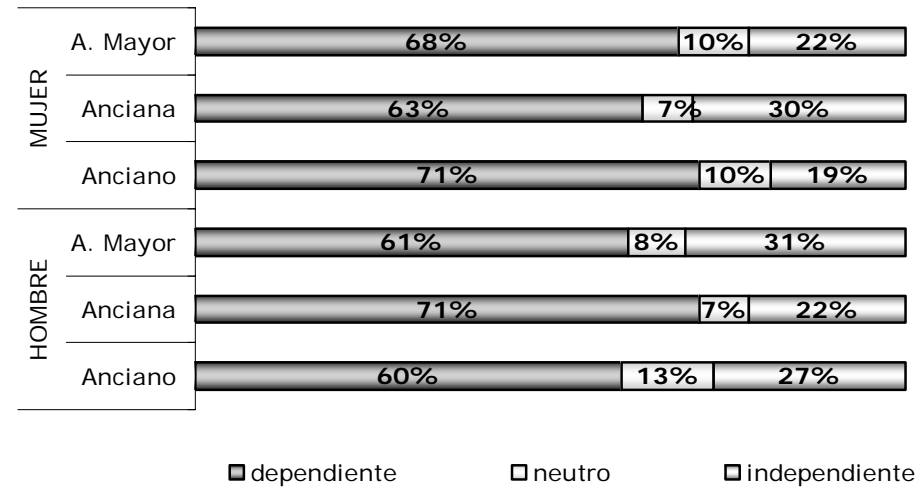

En cuanto a la "productividad", a pesar de que las tendencias son menos claras, podemos observar que las mujeres evalúan significativamente como más productivas a las ancianas (45\%) que a los ancianos (33\%) y a los adultos mayores (43\%). En el caso de los hombres, las diferencias significativas se dan entre adulto mayor $(43 \%$ los define como productivos) y anciana (34\%), por un lado, y anciano (35\%) por el otro.

Gráfico № 3: Tendencias obtenidas por hombres y mujeres en el par "Improductivo / Productivo", expresadas en porcentajes.

\section{I mproductivo / Productivo}

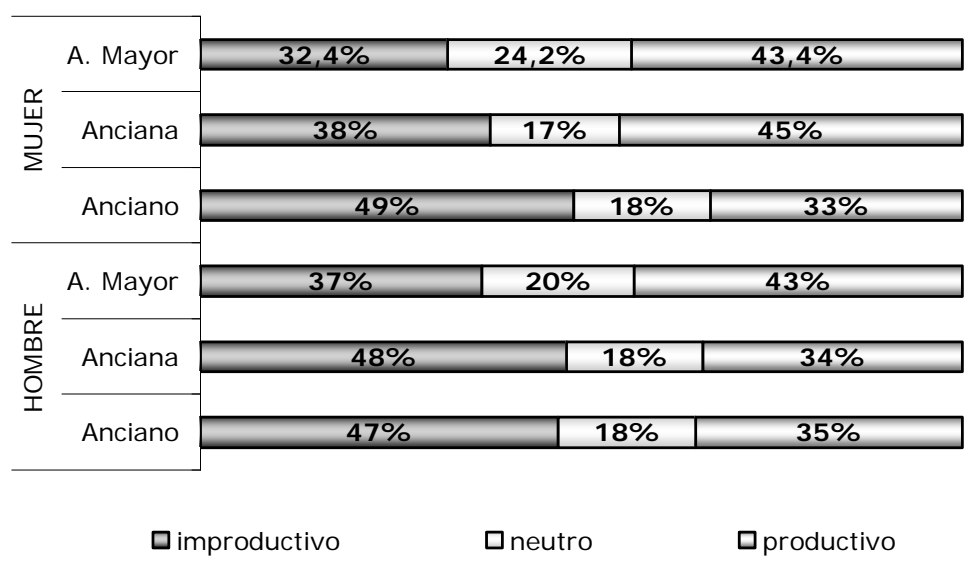

Frente al par adjetivo "ineficiente / eficiente" no encontramos tendencias relevantes. Las diferencias significativas que identificamos en la evaluación de las mujeres, están en la evaluación de anciano, quién es evaluado significativamente menos como eficiente (33\%) que para el caso de las ancianas (45\%) y adultos mayores (45\%). En la evaluación realizada por los hombres, la diferencia que identificamos está en que éstos evalúan significativamente como más ineficientes a las ancianas (40\%) que a los adultos mayores (30\%). 
¿Hay diferencias en la manera en que observan hombres y mujeres a los adultos mayores, ancianas y ancianos?

Gráfico № 4: Tendencias obtenidas por hombres y mujeres en el par “Ineficiente / Eficiente”, expresadas en porcentajes.

\section{I neficiente / Eficiente}

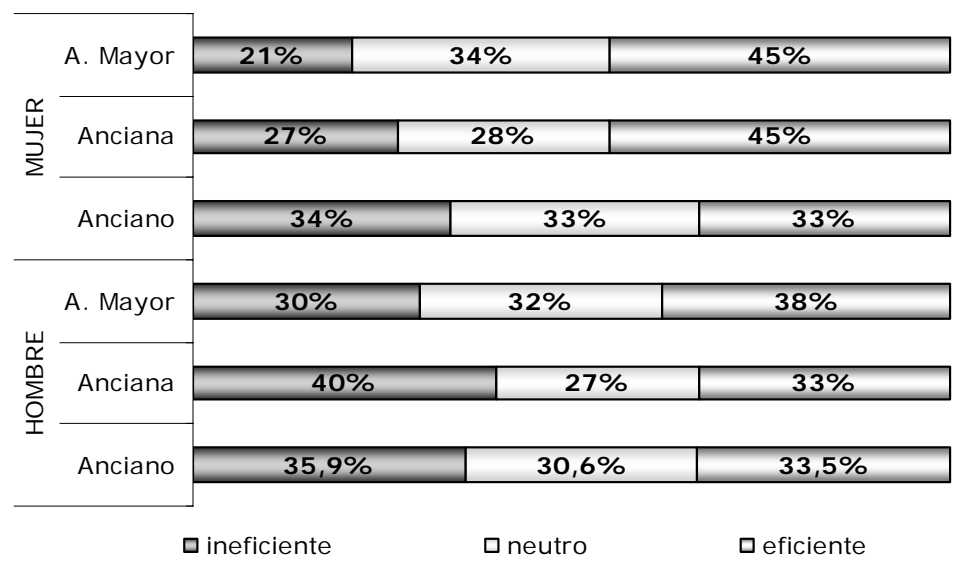

En cuanto a la "habilidad" o "torpeza" que se le asocia a la vejez, las mujeres evaluaron a los adultos mayores y ancianas con una tendencia al extremo "hábil" (45\% y $47 \%$ respectivamente) mientras al evaluar anciano presentaron una menor tendencia hacia este extremo (37\%). Las evaluaciones de los hombres no muestran una tendencia definida.

Gráfico № 5: Tendencias obtenidas por hombres y mujeres en el par "Torpe / Hábil", expresadas en porcentajes.

Torpe / Hábil

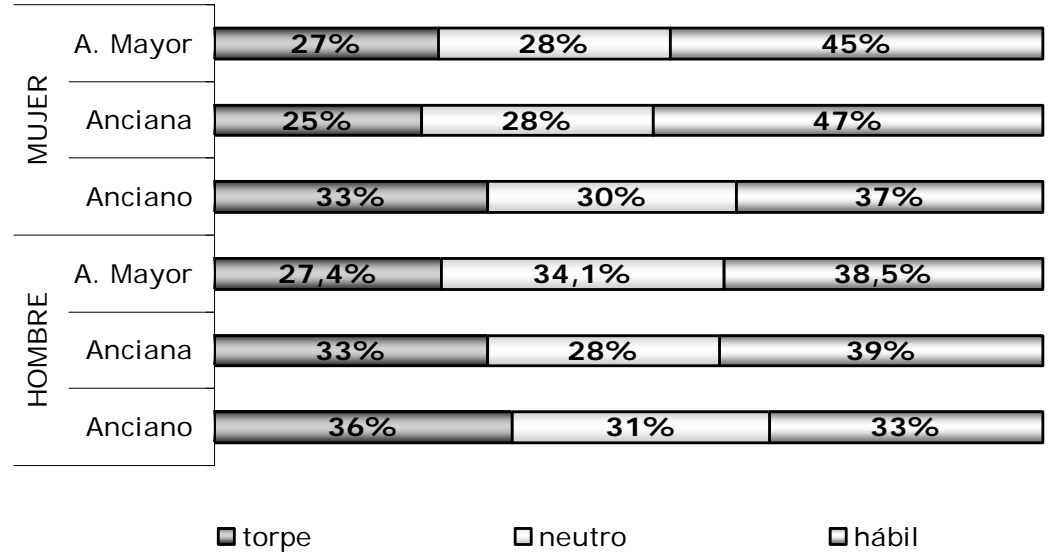

Frente al par adjetivo "enfermizo / saludable", tanto los hombres como las mujeres coincidieron en evaluar con tendencia al polo "enfermizos" a los tres grupos: adultos mayores, ancianas y ancianos. La única diferencia significativa que podemos identificar en estas evaluaciones es en la evaluación de los hombres, ya que más de ellos evalúan 
como enfermizos a los ancianos (68\%) que los que evalúan así a los adultos mayores $(59 \%)$.

Gráfico № 6: Tendencias obtenidas por hombres y mujeres en el par “Enfermizo / Saludable”, expresadas en porcentajes.

\section{Enfermizo / Saludable}

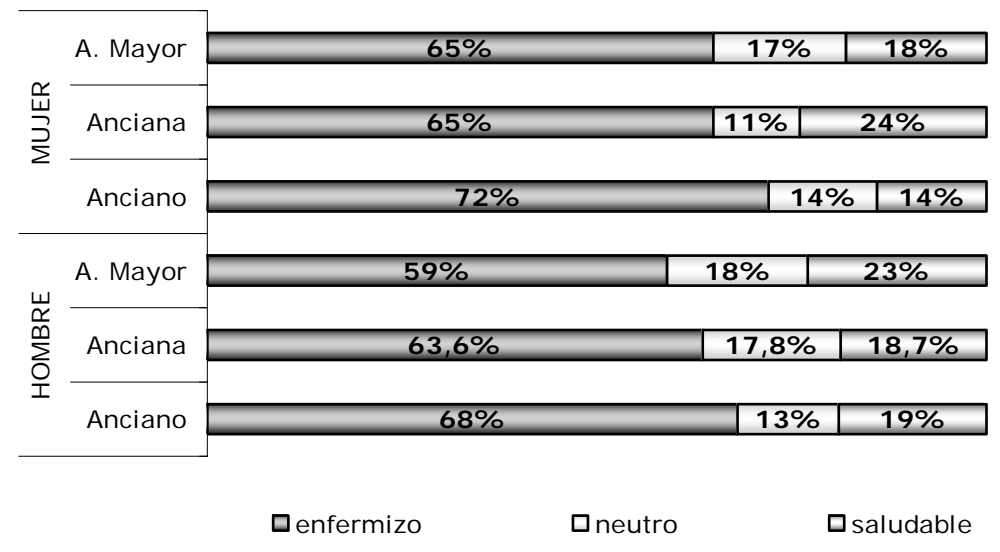

Frente al par "frágil / resistente" las evaluaciones muestran una clara tendencia hacia el extremo "frágil". Las diferencias significativas que encontramos están relacionadas con una mayor tendencia en la evaluación de anciana como frágil, en el caso de la evaluación de las mujeres, la diferencia la encontramos entre anciana (74\%) y anciano (65\%). En la evaluación de los hombres la diferencia es aún mayor, ya que evalúan anciana en un $81 \%$ como frágil, mientras al adulto mayor en un $66 \%$ y al anciano en un $65,3 \%$.

Gráfico № 7:

Tendencias obtenidas por hombres y mujeres en el par "Frágil / Resistente", expresadas en porcentajes.

Frágil / Resistente

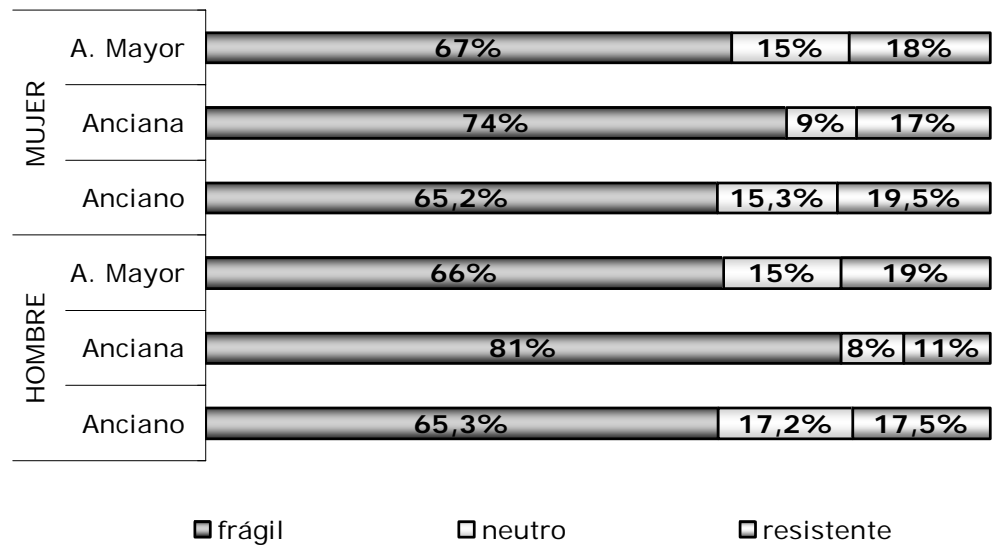

Revista Mad. $N^{\circ}$ 18, Mayo de 2008. Departamento de Antropología. Universidad de Chile http://www.revistamad.uchile.cl/18/urquiza_01.pdf 
Al evaluar la sexualidad en la vejez, los jóvenes muestran una clara tendencia a considerar a las personas mayores como "no activas sexualmente", por ambos géneros y para los tres reactivos estudiados. La única diferencia relevante que identificamos es en la evaluación de anciana que realizan los hombres, donde es evaluada significativamente más como no activa (73\%) que adulto mayor $(60,6 \%)$ y anciano $(63,3 \%)$.

Gráfico № 8: Tendencias obtenidas por hombres y mujeres en el par "Sexualmente no activo / Sexualmente activo", expresadas en porcentajes.

\section{Sexualmente no activo / Sexualmente activo}

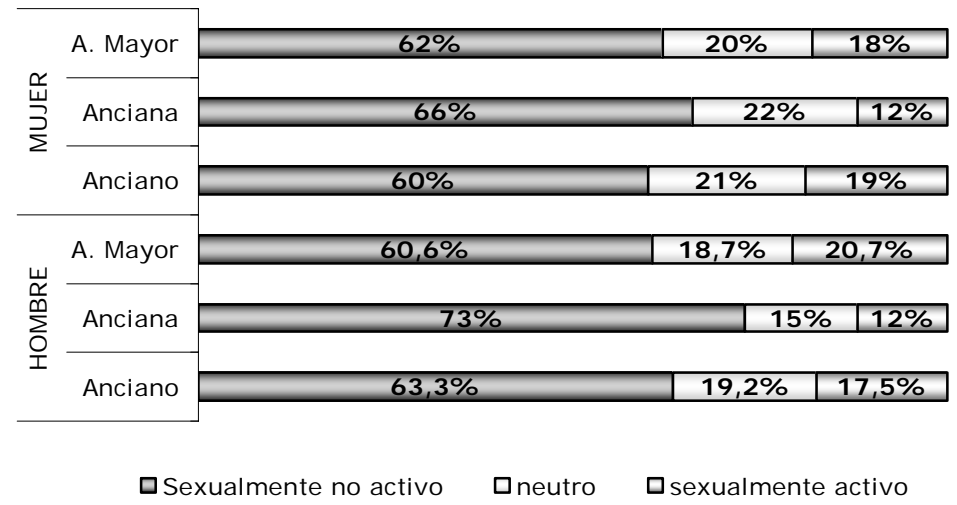

Respecto de la capacidad de "tolerancia" atribuida a las personas mayores, la tendencia, tanto de hombres como de mujeres, fue a evaluar a los ancianos como "intolerantes", mientras para el caso de las ancianas y los adultos mayores, no es posible identificar tendencias claras en la evaluación. Sin embargo, debemos destacar que tanto en la evaluación de las mujeres como la de los hombres, anciano es evaluado significativamente más como intolerante $(64 \%$ en el caso de las mujeres y $60 \%$ en el de los hombres) que las ancianas ( $42 \%$ mujeres y $41 \%$ hombres) y adultos mayores ( $41 \%$ mujeres y $43 \%$ hombres).

Gráfico № 9: Tendencias obtenidas por hombres y mujeres en el par “Intolerante / Tolerante”, expresadas en porcentajes.

I ntolerante / Tolerante

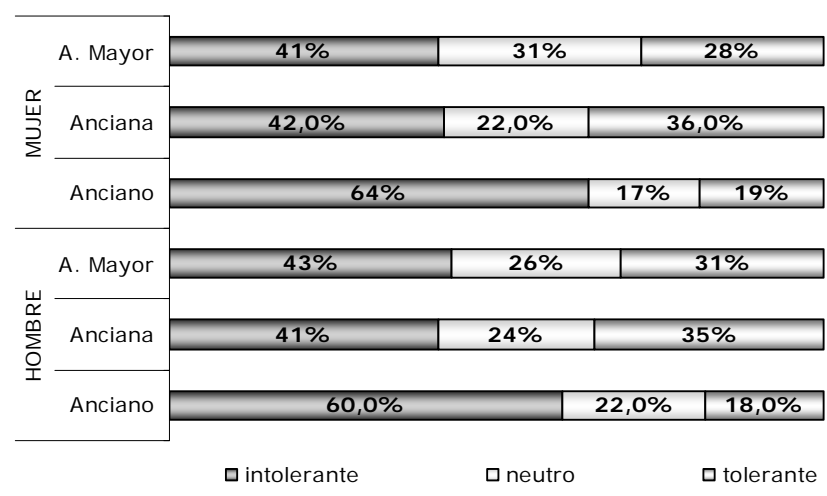


Frente al par de adjetivos "conservador / progresista", se observó una fuerte tendencia a estimar como "conservadores" a los tres reactivos del estudio, donde son los ancianos los que obtienen mayor evaluación en este sentido. Entre las diferencias relevantes encontramos que, para las mujeres, los ancianos son significativamente más conservadores $(80,24 \%)$ que las ancianas $(70,5 \%)$.

Gráfico № 10: Tendencias obtenidas por hombres y mujeres en el par "Conservador / Progresista", expresadas en porcentajes.

\section{Conservador / Progresista}

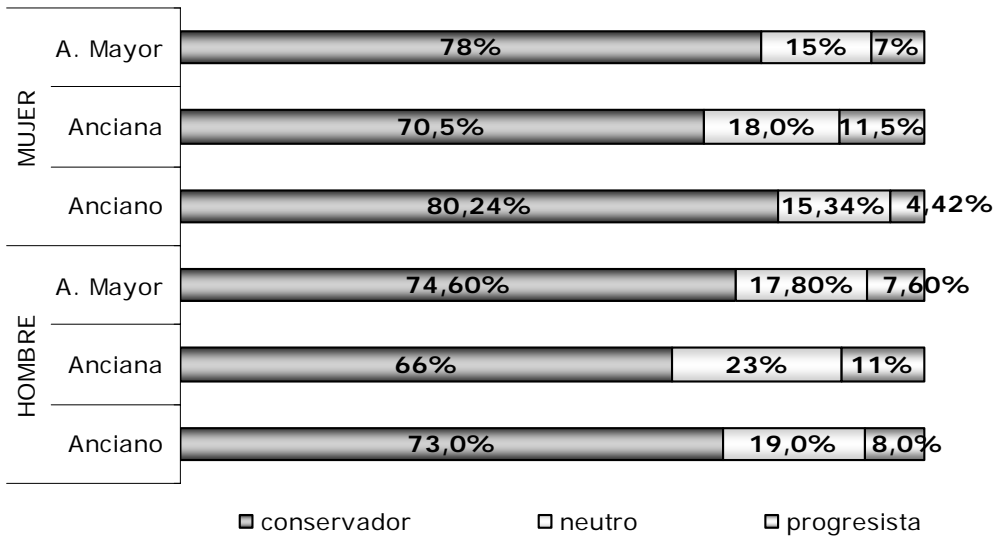

Frente al par de adjetivos "desconfiado / confiado", los jóvenes definieron a las personas mayores con una mayor tendencia al extremo "desconfiado". Las diferencias identificadas, tanto en hombres como mujeres, se refieren a una mayor evaluación de anciano como desconfiado (57\%) frente a adulto mayor $(47 \%$ mujeres, $42,3 \%$ hombres) y frente a anciana (46\%) en el caso de la evaluación que realizan los hombres.

Gráfico № 11: Tendencias obtenidas por hombres y mujeres en el par “Desconfiado / Confiado”, expresadas en porcentajes.

Desconfiado / Confiado

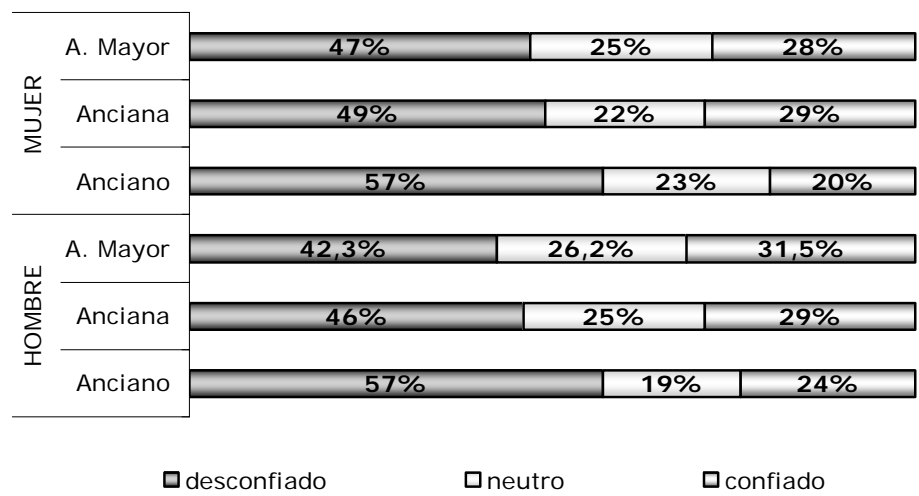

Revista Mad. $N^{\circ}$ 18, Mayo de 2008. Departamento de Antropología. Universidad de Chile http://www.revistamad.uchile.cl/18/urquiza_01.pdf 
Respecto de la imagen de "conflictivo" o "no conflictivo" que hombres y mujeres poseen de la vejez, sólo los ancianos fueron evaluados por ambos géneros con una clara tendencia al extremo "conflictivo" (47\% mujeres, $50 \%$ hombres) a diferencia de los adultos mayores (31\% ambos géneros) y ancianas (32,5\% mujeres; $35,3 \%$ hombres) para los que no hubo una tendencia clara en las evaluaciones.

Gráfico № 12: Tendencias obtenidas por hombres y mujeres en el par "Conflictivo / No conflictivo", expresadas en porcentajes.

\section{Conflictivo / No conflictivo}

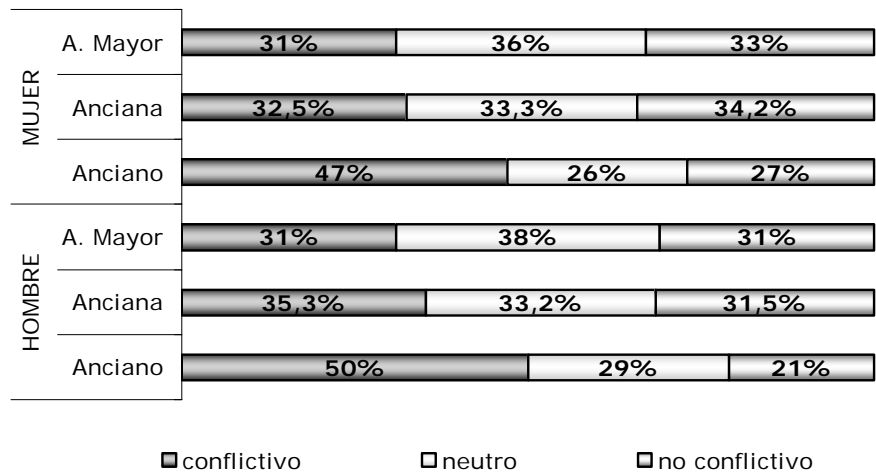

En cuanto a la "sociabilidad" asociada a la vejez, tanto los adultos mayores como las ancianas y ancianos fueron evaluados por hombres y mujeres con tendencia hacia el polo positivo, "sociable". Las diferencias significativas que identificamos se refieren a que más hombres y más mujeres evaluaron a las ancianas como sociable (58\% mujer, $65 \%$ hombres), frente a como evaluaron a los ancianos (43,7\% mujer, $45 \%$ hombre).

Gráfico № 13: Tendencias obtenidas por hombres y mujeres en el par "Retraído / Sociable", expresadas en porcentajes.

Retraído / Sociable

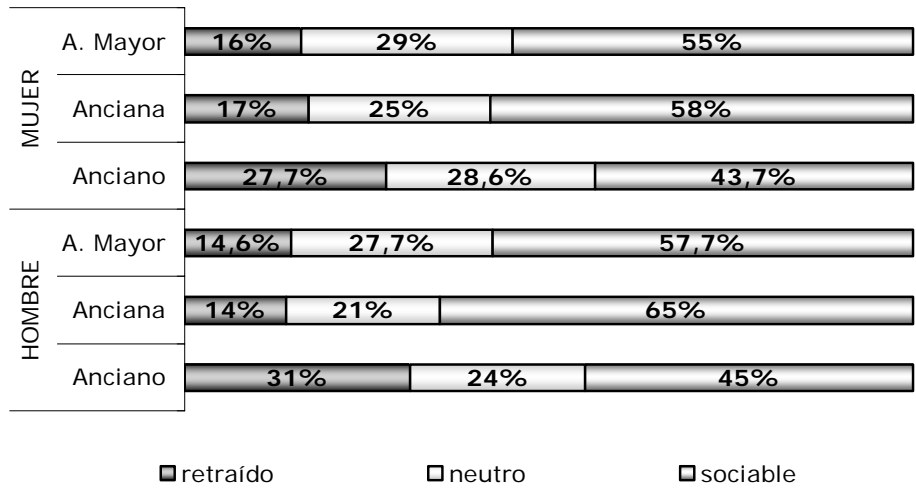


Al evaluar la participación en la sociedad de las personas mayores, no se observaron diferencias significativas. Tanto para los adultos mayores, como para las ancianas y ancianos se observó una tendencia a considerarlos como "ciudadanos pasivos".

Gráfico № 14: Tendencias obtenidas por hombres y mujeres en el par “Ciudadano Activo / Ciudadano Pasivo", expresadas en porcentajes.

\section{Ciudadano pasivo / Ciudadano activo}

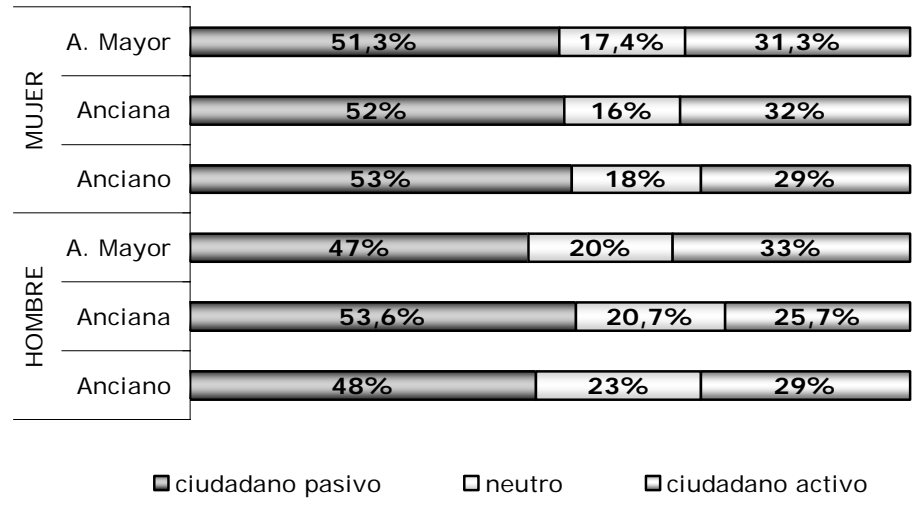

Respecto de la "protección" en que los jóvenes estiman que se vive en la vejez, tanto hombres como mujeres mostraron la tendencia a considerar a los ancianos y ancianas como personas "desamparadas". Para los adultos mayores hubo diferencias de apreciación en tanto hombres y mujeres mostraron una tendencia a definirlos como protegidos.

Gráfico № 15: Tendencias obtenidas por hombres y mujeres en el par "Desamparado / Protegido", expresadas en porcentajes.

\section{Desamparado / Protegido}

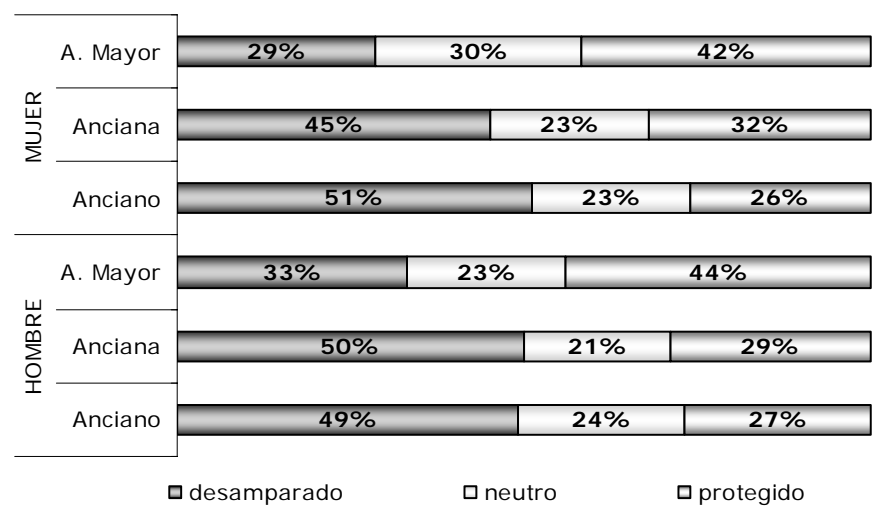

Respecto de la "integración" social que se considera tienen las personas mayores, tanto los hombres como las mujeres atribuyen a la vejez una clara tendencia a la "marginación" social. No hay diferencias en la evaluación de los jóvenes para cada concepto, desde sus perspectivas, adultos mayores, ancianos y ancianas estarían marginados socialmente. 
Gráfico № 16: Tendencias obtenidas por hombres y mujeres en el par "Marginado / Integrado", expresadas en porcentajes.

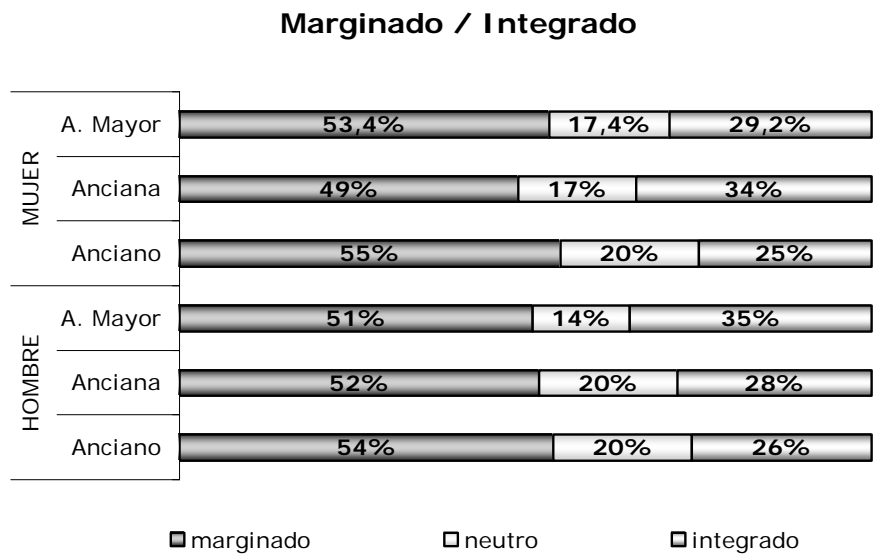

Finalmente, respecto de la valoración de la vejez, hombres y mujeres mostraron un consenso en considerarla con una clara tendencia a "desvalorado", sin que se observaran diferencias significativas en las evaluaciones de los tres reactivos frente a este atributo.

Gráfico № 17: Tendencias obtenidas por hombres y mujeres en el par “Desvalorado / Valorado", expresadas en porcentajes.

Desvalorado / Valorado

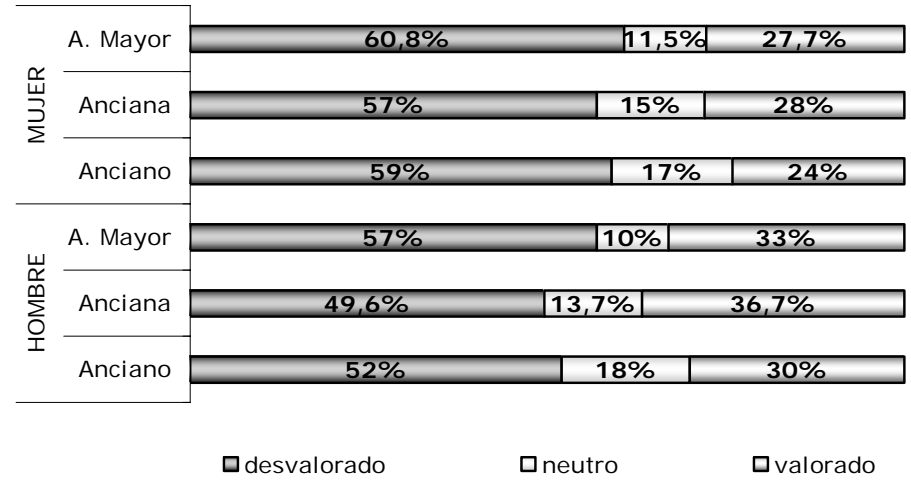

\section{Í ndices Generales de Consistencia de las Respuestas según género}

Para determinar la existencia de diferencias significativas respecto de la percepción global de hombres y mujeres frente a los tres reactivos, se construyeron índices generales. El procedimiento consistió en sumar los puntajes obtenidos por cada uno de los encuestados en cada una de las escalas de diferencial semántico, generando un puntaje final (en este caso una suma total) por sujeto para cada reactivo: adulto mayor, anciana y anciano. Estos tres puntajes finales fueron denominados índice de 
Percepción de Adulto Mayor, Índice de Percepción de Anciana e Índice de Percepción de Anciano, respectivamente.

Al someter los promedios obtenidos por los hombres en los tres Índices de Percepción a la prueba de Análisis de Varianza se constata que existen diferencias significativas en la percepción que realizan de los tres reactivos.

Tabla № 2: Resultados Análisis de Varianza de los promedios de los Índices de Percepción (Hombres)

\section{ANOVA HOMBRES}

INDICES

\begin{tabular}{|l|l|l|l|l|l|}
\hline & \multicolumn{1}{|c|}{$\begin{array}{c}\text { Suma de } \\
\text { cuadrados }\end{array}$} & \multicolumn{1}{|c|}{ GI } & \multicolumn{1}{|c|}{$\begin{array}{c}\text { Media } \\
\text { cuadrática }\end{array}$} & \multicolumn{1}{|c|}{ F } & Sig. \\
\hline I nter-grupos & 3905,252 & 2 & 1952,626 & 12,523 & 0 \\
\hline I ntra-grupos & 156700,168 & 1005 & 155,921 & & \\
\hline Total & 160605,42 & 1007 & & & \\
\hline
\end{tabular}

Con objeto de determinar la localización de la diferencia significativa se aplicó el Test de Scheffé para comparaciones múltiples de medias. El resultado indicó que los hombres perciben de distinta forma al Adulto Mayor respecto de la Anciana y del Anciano, pero no establecen diferencias significativas entre Anciana y Anciano. En otras palabras, en la organización perceptual que presentan los estudiantes de sexo masculino, la noción de anciana y anciano se posicionan en un mismo punto, mientras que la noción adulto mayor se ubica distanciadamente, diferenciándose de los primeros. En relación al sentido de la diferencia, se constata que los hombres perciben en forma más positiva al Adulto Mayor que a las Ancianas y Ancianos.

Tabla № 3: Resultados Test de Scheffé (Hombres)

Comparaciones múltiples

\begin{tabular}{|c|c|c|c|c|c|}
\hline \multicolumn{6}{|c|}{ Variable dependiente: INDICE } \\
\hline & ( I ) REACTI VO & (J) REACTI VO & $\begin{array}{l}\text { Diferencia de } \\
\text { medias (I-J) }\end{array}$ & Error típico & Sig. \\
\hline \multirow{6}{*}{ Scheffé } & \multirow{2}{*}{ Adulto Mayor } & Anciana & $3,65(*)$ & 0,969 & 0,001 \\
\hline & & Anciano & $4,62(*)$ & 0,969 & 0 \\
\hline & \multirow{2}{*}{ Anciana } & Adulto Mayor & $-3,65(*)$ & 0,969 & 0,001 \\
\hline & & Anciano & 0,97 & 0,969 & 0,594 \\
\hline & \multirow{2}{*}{ Anciano } & Adulto Mayor & $-4,62(*)$ & 0,969 & 0 \\
\hline & & Anciana & $-0,97$ & 0,969 & 0,594 \\
\hline
\end{tabular}

* La diferencia entre las medias es significativa al nivel .05.

\begin{tabular}{|c|c|c|c|c|}
\hline & \multirow{2}{*}{ REACTI VO } & \multirow{2}{*}{$\mathbf{N}$} & \multicolumn{2}{|c|}{ Subconjunto para alfa $=.05$} \\
\hline & & & 1 & 2 \\
\hline \multirow{4}{*}{ Scheffé(a) } & Anciano & 343 & 55,31 & \\
\hline & Anciana & 343 & 56,28 & \\
\hline & Adulto Mayor & 322 & & 59,93 \\
\hline & Sig. & & 0,6 & 1 \\
\hline
\end{tabular}


Para el caso de las mujeres, como se aprecia en los siguientes dos cuadros, los resultados también indican la existencia de diferencias significativas entre los tres promedios de los Índices de Percepción, pero éstas fueron distintas a las obtenidas por los hombres. La comparación múltiple de promedios indicó que las mujeres distinguen entre Anciano y los otros dos reactivos, quedando en posiciones similares los términos Adulto Mayor y Anciana en la organización perceptual que realizan, mientras que Anciano queda posicionado en un punto distinto, diferenciándose de los primeros. Considerando el sentido de la diferencia, se concluye que las mujeres perciben los ancianos en forma más negativa que a las ancianas y los adultos mayores.

Tabla № 4: Resultados Análisis de Varianza de los promedios de los Índices de Percepción (Mujeres)

ANOVA MUJ ERES

INDICE

\begin{tabular}{|l|l|l|l|l|l|}
\hline & $\begin{array}{c}\text { Suma de } \\
\text { cuadrados }\end{array}$ & \multicolumn{1}{|c|}{ GI } & $\begin{array}{c}\text { Media } \\
\text { cuadrática }\end{array}$ & \multicolumn{1}{|c|}{ F } & Sig. \\
\hline I nter-grupos & 5216,986 & 2 & 2608,493 & 15,455 & 0 \\
\hline I ntra-grupos & 168783,186 & 1000 & 168,783 & & \\
\hline Total & 174000,171 & 1002 & & & \\
\hline
\end{tabular}

Tabla № 5: Resultados Test de Scheffé (Mujeres)

Comparaciones múltiples

Variable dependiente: INDICE

\begin{tabular}{|c|c|c|c|c|c|}
\hline & (I) REACTI VO & (J) REACTI VO & $\begin{array}{l}\text { Diferencia de } \\
\text { medias }(I-J)\end{array}$ & Error típico & Sig. \\
\hline \multirow{6}{*}{ Scheffé } & \multirow{2}{*}{ Adulto Mayor } & Anciana & 1,13 & 0,937 & 0,914 \\
\hline & & Anciano & $5,30(*)$ & 0,937 & 0,001 \\
\hline & \multirow{2}{*}{ Anciana } & Adulto Mayor & $-1,13$ & 0,937 & 0,914 \\
\hline & & Anciano & $4,17(*)$ & 0,937 & 0,006 \\
\hline & \multirow{2}{*}{ Anciano } & Adulto Mayor & $-5,30(*)$ & 0,937 & 0,001 \\
\hline & & Anciana & $-4,17(*)$ & 0,937 & 0,006 \\
\hline
\end{tabular}

* La diferencia entre las medias es significativa al nivel .05.

I NDI CE MUJ ERES

\begin{tabular}{|l|l|l|l|l|}
\hline \multirow{2}{*}{ REACTI Vo } & \multicolumn{2}{|c|}{$\mathbf{N}$} & \multicolumn{2}{c|}{ Subconjunto para alfa $=.05$} \\
\cline { 3 - 5 } & & & $\mathbf{1}$ & $\mathbf{2}$ \\
\hline \multirow{4}{*}{ Scheffé(a) } & Anciano & 339 & 53,65 & \\
\cline { 2 - 5 } & Anciana & 339 & & 57,82 \\
\cline { 2 - 5 } & Adulto Mayor & 325 & & 58,94 \\
\cline { 2 - 5 } & Sig. & & 1 & 0,533 \\
\hline
\end{tabular}

En síntesis, tanto hombres como mujeres perciben de distinta forma los tres reactivos consultados. Los hombres perciben a nivel general de manera más positiva a los adultos mayores que a las ancianas y ancianos, sin realizar distinciones entre estos dos últimos términos. Mientras que las mujeres perciben más positivamente al adulto mayor y a las ancianas que a los ancianos, sin establecer distinciones relevantes entre los dos primeros términos. 


\section{Conclusiones}

Cuando nos aproximamos desde la antropología social a la vejez, nos vemos obligados a considerar que las categorías de edades son construcciones culturales (Feixa, 1996). Al respecto, uno de los aspectos centrales a preguntarse es si la variable género es relevante al momento de construir imágenes sobre la vejez.

Hemos podido constatar que las atribuciones que aplican los jóvenes chilenos, tanto hombres como mujeres, a la vejez y envejecimiento apuntan a una idea de decadencia. Sin proponérselo, tanto los jóvenes como las jóvenes, generalizan estereotipos que no se empalman con las actuales posibilidades de los adultos mayores y que, por el contrario, estimulan su resignación y fatalismo. A pesar de que hemos logrado identificar algunas diferencias interesantes en las evaluaciones de hombres y mujeres, son más importantes los consensos en sus evaluaciones. En este sentido, creemos que el hecho que el género no aparezca como una variable determinante en la construcción de la imagen de la vejez, da cuenta del enorme peso que el estereotipo negativo sobre esta etapa de la vida tiene en nuestra sociedad, trascendiendo las diferencias de género. Más aún, si consideramos lo señalado por Moen y Spencer (2006) respecto de la ambigüedad e incertidumbre para definir un estilo de vida en la vejez, dados los actuales cambios sociales, podemos suponer que nuestros jóvenes están lejos aún de cuestionar los estereotipos con que observan la vejez.

Todo lo anterior contribuye a la configuración de un entorno social que tiene mucho de gerontofóbico. Desgraciadamente, estos estereotipos contenidos en las imágenes sociales indicadas, condicionan a los ancianos a aceptar "una realidad" montada sobre prejuicios que finalmente hacen suya, padeciendo las consecuencias de ello. Por otra parte, muchos adultos mayores se ajustan irrestrictamente a las convenciones sociales con respecto a los comportamientos esperados a sus edades cronológicas y que han sido construidas en base a condiciones ya superadas por los cambios económicos y médicos, lo cual constituye un contrasentido. Por ejemplo, al llegar a la edad de jubilación las personas pueden sentirse presionadas por cumplir las expectativas de retiro del mundo laboral aun cuando estén en condiciones y tengan los deseos de seguir trabajando o, como es conocido, abandonan tempranamente su vida sexual y afectiva. En este contexto no es extraño que muchas de las personas que se aproximan a la vejez se enfrenten a una lucha por aferrarse a las cualidades propias de una juventud idealizada, lo que les puede generar por consecuencia importantes sentimientos de frustración.

Por lo señalado, creemos que comenzar a develar las imágenes que predominan en nuestra sociedad sobre la vejez puede resultar un aporte a su reflexión y cuestionamiento. Consideramos que ello constituye un paso en la dirección de cambiarlas y con ello mitigar sus efectos no deseados, en tanto las oportunidades de las personas mayores se ven frenadas ante las imágenes negativas que se les extienden. RM

\section{Bibliografía}

ADELANTADO F., SEGURA, C., DE ANDRÉS J., FELIU T., MARTÍ NEZ P. "Los mayores de 85 años en Sabadell", En: Revista Multidisciplinar de Gerontología № 14 (5), Pág. 271278, 2004, España. 
AGUI LERA, M. 2005. "Las Nuevas Proyecciones de Población." Instituto Nacional de Estadísticas, 2005. Disponible en:

http://www.eclac.cl/celade/noticias/paginas/7/22677/Maguilera.pdf (acceso 01/10/06).

ARNOLD, M. 2003. "Fundamentos del Constructivismo Sociopoiético". Cinta de Moebio, $N^{\circ}$ 18, Revista Electrónica de Epistemología de las Ciencias Sociales, Facultad de Ciencias Sociales, Universidad de Chile. Disponible en:

http://rehue.csociales. uchile. cl/publicaciones/moebio/18/arnold01.htm (acceso:

06/10/06)

BRAVO, J., BERTRANOU, F. “Evolución Demográfica y Pensiones en Chile”. OIT Notas, № 4, junio 2006.

FEIXA, C. 1996. "Antropología de las edades". En: Ensayos de Antropología Cultural. Homenaje a Claudio Esteva-Fabregat. J. Prat \& A. Martínez (eds.) Editorial Ariel / Barcelona, España. Publicación virtual Biblioteca virtual de Ciencias Sociales www. cholonautas.edu.pe (acceso: 26/09/06).

GEORGE, L. 2006. "Perceived Quality of Life".. In: Handbook of Aging and the Social Sciences. Binstock, R. and George, L. Ed. Academic Press. Amsterdam.

INE, 2004. "Estimaciones y proyecciones de población por sexo y edad". I nstituto Nacional de Estadística. Disponible en http://www.ine.cl/canales/chile_estadistico/home.php

LUHMANN, N. 1998. Die Gesellschaft der Gesellschaft, Suhrkamp Taschenbuch Wissenschaft 1360, Suhrkamp Taschenbuch Verlag, Frankfurt am Main.

MOEN, P., SPENCER, D. 2006. "Converging Divergences in Age, Gender, Health, and Well Being. Strategic Selection in the Third Age". In: Handbook of Aging and the Social Sciences. Binstock, R. and George, L. Ed. Academic Press. Amsterdam.

OSGOOD, CH.., G.J.SUCI \& P.H.TANNENBAUN, 1957. The Measurement of Meaning. Urbana, University of Illinois Press.

SENAMA: Cifras Mayores (Número de adultos mayores en Chile según datos del Censo 2002 del Instituto Nacional de Estadísticas, INE). Disponible en:

http://www. senama.cl/Archivos/968.pdf (access: 21.11.06)

SENAMA. I nforme Del Comité Nacional Para El Adulto Mayor 2002. Encuesta Imagen de la Vejez. Santiago: Available in: http://www.senama.cl/Archivos/716.pdf (access 11.12.06)

TAN P., ZHANG N., FAN L. 2004. “Students' attitudes toward the elderly in the people's republic of China". Educational Gerontology № 30: Pág. 305-314, 2004.

TORREJ ÓN, M.J . 2007. Imaginario social de la vejez y el envejecimiento. Análisis de contenido de prensa escrita. Tesis para optar al Grado de Magíster en Antropología y Desarrollo, Facultad de Ciencias Sociales, Universidad de Chile.

UNESCO, 1997. Clasificación Internacional Normalizada de la Educación. Organización de las Naciones Unidas para la Educación, la Ciencia y la Cultura. Disponible en: 
http://portal.unesco.org/education/es/ev.php-

URL_ID=36031\&URL_DO=DO_TOPIC\&URL_SECTION=201.html (acceso: 23/03/06)

ZIKMUND, W. 1998. Investigación de Mercados. Sexta edición. Prentice Hall. México.

\section{Notas}

\footnotetext{
1 Investigación desarrollada en el marco del proyecto Anillos de Ciencias Sociales patrocinado por la Comisión Nacional de Ciencia y Tecnología (CONICYT) y el Banco Mundial. Este artículo contó con la colaboración de las sociólogas Florencia Jensen y Natalia Vogel, asistentes de investigación del Programa de Magíster en Antropología y Desarrollo de la Universidad de Chile, y la asesoría de Tamara Arnold como analista cuantitativa.
} 